\title{
Our Generation at Risk: Tale of Disintegrated Families' Children in Areas of Pakistan: A Review
}

\author{
Sohni Siddiqui ${ }^{1}$, Dr. Naureen Nazar ${ }^{2}$, Yasmeen Mehboob ${ }^{3}$ \\ ${ }^{1}$ (Ph.D Research Scholar), Department of Education Psychology, Technical University, Berlin \\ ${ }^{2}$ (Ph.D from University of York) Assistant Professor, University of Sindh \\ ${ }^{3}$ (M.Phil-Education), Department of Education and Social Sciences, Iqra University. Lecturer Aga Khan \\ University, Karachi \\ Corresponding author‘s email: zahid.sohni@gmail.com, s.zahid@campus.tu-berlin.de
}

\begin{abstract}
Constitutional Protection has been given to marriages and families throughout the world, to give healthy milieu for nurturing and fostering positive attitude among children. Unfortunately, lack of patience, an absence of compromise, prevalent greed and other such reasons has increased matrimony challenges throughout the world and has shown a rise in divorce rates. The purpose of this paper is to find out consequences faced by children of disintegrated families in Pakistan and to suggest remedies to overcome these concerns among children. Conclusions are made on the basis of narrative literature review to highlight consequences and solutions. Increase in divorce rate is also getting common in Pakistan and has brought poor development in children's growth, adding negative factors in children's personalities. The results are worse if domestic violence and continuous conflicts amongst parents take place. Such children develop psychopathological disorders which continue throughout their lives. Matrimony challenges have influenced dropout rate throughout the world including Pakistan and have resulted in the decline in literacy rate in a new generation. Moreover, in the case of parental separation, kids have additional freedom to indulge in social networking sites, leading to the attainment of undesirable characters in their personalities, which later surges into acts of delinquency and crime. In order to overcome such weaknesses developed in children due to lack of parental attention, some remedial strategies such as adults' supervision, counseling session, strong policies, financial assistance, government support etc are suggested in later part of this research.
\end{abstract}

Keywords: Disintegrated Families, Divorce, Government's Support, Matrimony challenges, Psychopathological Disorders.

\section{Introduction}

The study is designed for the purpose of focusing upon problems faced by children from disintegrated families. Families with single parent, suffer from different complexes leading to the destruction of their personalities. Many of the researches suggested that disintegration of family has always brought wide range of hostile effects on children's development, not only to temporary basis but it continues and persist even when child transit into an adulthood (Mackay, 2005; Falculanet al., 2019; Ayobami, 2021). Some of the effects are associated with problems in schooling, physical health, social conduct, behavior, mental and emotional health, early marriage, marital dissolution and mistrust. It is believed by sociologists, policymakers and people from diversified societies that presence of both parents is the most suitable environment for children's holistic growth (McGuirk \& Mai, 2016). Those children are considered blessed who born into strong families, which benefit them almost in every area, throughout their lives including, physical fitness, educational achievement, maintaining healthy long-lasting relationships, success in securing and keeping a well-paid job (Demir-Dagdas et al., 2018; Wardle, 2011). However, if children are born; into conflicting disintegrated families, still some of their negative developments can be controlled by replacing parents' absence with other mature adults, teachers, by providing social security, financial aid etc.

\subsection{Research Objective}

To find out consequences faced by children of disintegrated families in Pakistan and to suggest remedies to overcome these concerns among children, with the help of narrative literature review. 


\subsection{Research Questions}

What are the consequences of disintegrated families on the development and nurturing of children?

How to control divorce rate and sufferings of children from broken families?

\subsection{Research Methodology}

Qualitative approach where narrative literature review is used for gathering data and generating research questions. Secondary data is collected from e-books, research articles, research journals, newspapers, reports and websites.

\section{Literature Review}

The narrative or traditional literature review is employed for the present work. Narrative reviews are one of the useful literature reviews in a sense that it brings the useful information together at one place. It helps presenting philosophical perspectives in a balanced manner (Green, Johnson, \& Adams, 2006). Narrative literature reviews helps researcher drawing conclusions about the literature.

\section{Parental Bonding and Its Importance}

Good parenting requires enough teamwork to assure not only back up of another parent but more significantly, to insure integration of qualities, skills, vision and perception of both male and female characters within them. Father and Mother not only teach respect for each other but have different styles of loving, instructing and caregiving (Wardle, 2011).

Parent alone may be an outstanding caregiver but is not sufficient to provide more affluent environment for a child's development, unless they are in contact with people from outside to get rich, diversified roles, activities and experiences require for child's development. Mothers usually after divorce or separation, lead to professional activities which definitely make them busy and reduces quality time with children, requires for nurturing with purposeful and co-operative activities (Demir-Dagdas et al., 2018). Along with parents' disintegration, other factors such as modern lifestyle, age segregation, extensive technology use, concept of privatism, have also inclined parents towards spending lesser time with them (Garbarino, 2009).

Parental break up is not only associated with negative outcomes in earlier lifecycle, but it continues throughout the life when child is young, teenager, mature or even when developed into senior citizen. Children coming from broken families reported problems associated with fear, trust issues, poor self-worth, and relationship problems (Falculanet al., 2019). Offspring of separated couples are found poor, illiterate, or less educated, involved in hazardous sexual deeds, causing pre-marital pregnancies, have earlier wedding, and most of the time have unsuccessful married lives. Due to discussed factors, along with these negative aspects, emotional instability also increases especially among young adult hood. However, extent of divorce mechanisms which influence such behaviors, needs to be discovered (D’Onofrio, 2011).

Divorce is considered to be immoral practice in many religions, as it adversely affects not only the individuals but whole society in many ways, such as divorce declines the regularity of worship of God following abate the faith and believe on God existence, divorce reduces children's interest towards educational attainment and increases dropout. Due to separation, single parent household income becomes insufficient to carry out moderate lifestyle ((Demir-Dagdas, 2018). Divorce is also associated with surge in crime rate, exploitation, negligence and narcotics use. One of the most adverse effect of parents' segregation is on children's physical as well as psychological health, increasing emotional issues, and psychiatric risks, including suicide attempts (Churchill, 2012). However, extent of such effects varies from case to case and is found at different levels in different cases (D’Onofrio, 2011).

\section{Increasing divorce rate in pakistan}

Marriages are considered as institutions to develop happy families and healthy relationships among parents and their offspring (Ramzan et al., 2018). Unfortunately, these foundations are now considered at risk in Pakistani culture too, as divorce rate along with different parts of the world also has ascended in Pakistan (Ramazan et al., 2018; Waseem et al., 2020). In Pakistani social circles, a divorce or separation is considered as shame to the family and creates disturbances among members. But this shameful act is getting common day by day due to lack of compromise, dominancy of spouses, in-laws' pressure, financial problems, early marriages, extra marital affairs, forced marriages, greed etc. (Tariq, 2009). According to Freud's Displacement Theory, a person will displace their anger at something onto someone else. This theory is also applicable in case of spouses, when one of the member sheds frustration onto other, and continuous conflicts lead towards the end of relationship (Nizamuddin, 2017). According to data, in the province of Punjab in 
year 2012, 13,299 Khula (right of women to seek divorce) cases were reported. Later in 2013, Khula rate was increased to 14,243. Continuous rose displayed in 2014, when 16,942 and in 2016 when 18,901 cases declared in courts

(Anonymous, Rising Divorce Rates, 2016). Of 2010, in Karachi, a total of 40,410 divorce cases were reported in courts. It has been reported about 150 divorce cases are reported daily in courts in Lahore, evidencing high divorce rate in Pakistan. However, in Khyber Pakhtunkhwa despite the highest violence rate, separation of parents and disintegration of families are least reported as domestic violence is a common practice and accepted as a part of the culture (Fig I). Similarly, in rural areas despite the prevalent violence, divorce cases are hardly reported and seen.

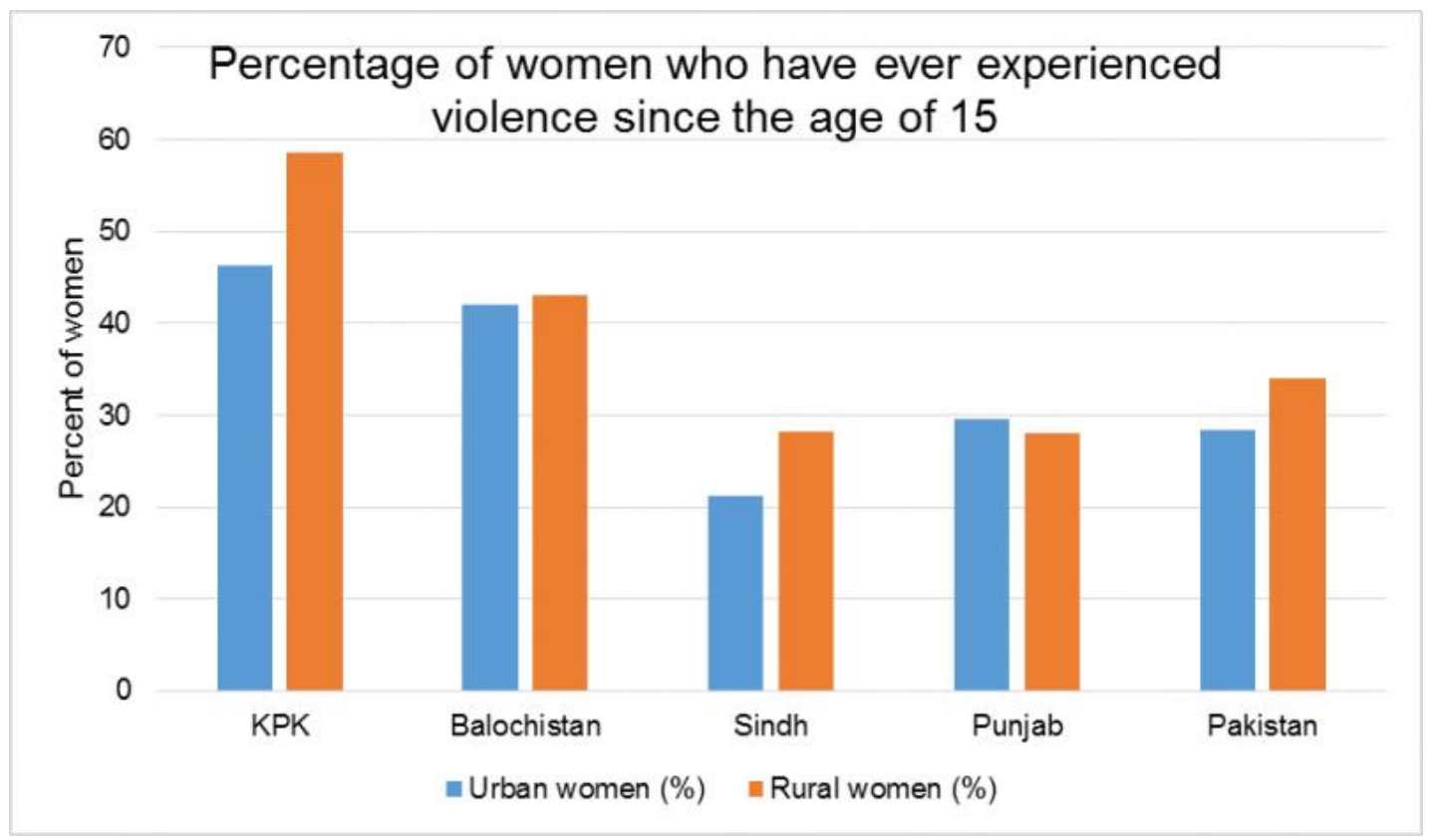

Figure No. 1. The continued abuse of the Pashtun woman, Haider, M. (2014, Feburary 19). Retrieved from Dawn News: https://www.dawn.com/news/1088086

Lack of education and acceptance of domestic violence against women as a cultural norm has made KPK and Baluchistan, the epicenter of militancy and terrorism where children, witnessing violence regularly start believing such ferocious acts are acceptable and practical (Haider, 2014).

It has also been proven that children of the disintegrated relations suffer from different psychological and physical complications. These harms are getting common among Pakistani kids too, as divorce rate in recent years has been augmented, thus misery and negative consequences are integrated among the children in the society.

\subsection{Disintegrated Families' Children Health And Psychological Issues}

One of the chief consequences with children of dissociated families is related with improper physical growth, and associated health issues (Goisis, Özcan \& Van Kerm, 2019). One of the reasons behind improper growth can be absence of mother either due to separation and if she has custody of the children, her engagement in some labor activity to provide financial support to the family, make her unavailable for children. Other reasons can be insufficient financial incomes for proper nourishment of children, as single parent have less monetary resources (Demir-Dagdas, 2018; Churchill, 2012). Parental segregation during childhood appeared as one of the strongest causes behind early death in adulthood. Researchers believe that children of disintegrated families have almost five years lesser life span, then off springs of families with healthy companionship. Few of the explanations of lesser life span ranged from calamities in accidents, death due to diseases like cancer, heart attack and stroke. Researchers consider that among the most disturbing and damaging happenings for children is separation of parents (Wardle, 2011). 
Psychological harms among children from disintegrated families ranges from anxieties, fears (Philpott, 2013) to depression, distress symptoms, lack of self-esteem, lack of self-efficacy (McGuirk \& Mai, 2016) and insomnia panic attacks. In our culture, even the word divorce bears a stigma which creates anxiety, frustration, and inferiority complexes among the left-over children. End of the relationship not only affects divorced couple but, children of broken homes are at risk of developing mental health problems. Punjab University researcher has concluded that children from disintegrated families lack self-assurance, however warm and nurturing parents have children with high self-confidence (Nizamuddin, 2017). Many disturbed children answer to trauma by showing split personality character. These children cannot handle different emotional obligations and represent themselves as differently in different situations (Streeck-Fischer \& van der Kolk, 2000).

It has been reported that children from broken families are more indulged in unsafe sex activities (Harold \& Sellers, 2018; Hetherington, 1972). In Pakistan, such stories surface where not only adults, but also young adolescents are involved in dangerous sexual practices (Towe et al., 2009). Hormonal changes taking place at the time of adolescence need proper guidelines to deal with such natural phenomena, but missing surveillance of parents and unguided education lead towards such destructions (Jivani \& Minaz, 2019). Parental absence establishes deprivation of a child learning, when growing up from young to adolescences.

Wardle (2011) in his studies suggested that youth who report risky sexual behavior are at elevated risk for adverse health consequences, such as involvement in suicidal attempts, indulgence in harassment and school violence, adoption of drug and alcohol abuse, unhealthy eating habits and teenage pregnancy etc. These actions are associated due to parental divorce and are more common if a child is raised by a single parent.

Divorce of parents can result in social isolation of children as readjustment is difficult. Financial problems often follow divorce, especially when a woman is left with children to raise them, with no support system. In order to cope up with financial problems, children leave their schooling and engaged in professions not suitable for their character's development, leading towards the de-learning and acquiring negative aspects of the society. In some cases, children become attention seekers (Hetherington, 1972; Pickhardth, 2011) and they do whatever pleases them (Muhid \& Kurniadi, 2021). They try to win their parent's attention by misbehaving, crying, arguing, doing immature activities etc. But if caregiver is unable to realize these tricks of attainment of attention, such children start to use tactics to gain attention of others, such as their peers and often act dishonorably to gain popularity or to become a part of popular narrations and to be part of conversations of others (Magpantay et al., 2014). Research evidence the cases, where children with the purpose to gain attention, start to behave strangely, by the way they communicate and interact differs from other children of their age. Sometimes they share disrespectful posts such as shameful picture, dancing videos, disgraceful acts on social media just to get popularity and attention among peers.

\subsection{Reduced Educational Accomplishments and High Dropout Rate}

Parental separation is one of the causes of educational complications, including low scores in academics, high dropout rate and troublesome actions in school such as excessive indulgence into fights, stealing, using foul language or using illegal drugs (D’Onofrio, 2011; Ngure, Paul \& Amollo; 2017). Australian researcher has also revealed same patterns in separated families' children and explained that children from disintegrated family showed disrupting behavior at elementary stage of schooling, had weaker emotional bonding and poor scores in achievement tests. Juveniles from separate parents in high school exhibited higher dropout rate in school as compared to kids of two parental families (Paula Fomby, 2007). Divorce creates psychological problems such as anxiety, insomnia, panic attacks on the left-over members of family which diminishes child's concentration in studies and creates sufferings in academics. Research conducted by Wardle says that the children from discord families do not reach up to the bachelor's level of education and usually leave studies at early stage of academics. As a result, unable to get high paid jobs and in return, have financial problems which increases possibility of divorce when they get into marital relationship. It was estimated in 1990s, USA citizens with higher qualifications were less likely to divorce and the rate dropped from 22 percent to 19 percent. On the contrary, high school diploma holders had higher tendency of separation and the percentage increase was 34 percent to 42 percent. Worst rose was observed to $45 \%$ with citizens, without certificate of completion of school (Wardle, 2011). In Pakistan, elevated dropout rate is getting common especially in rural areas. This drop out might be associated with violence and extreme punishments at school but financial constraint, psychological issues and absence of parents after separation or divorce is one of the major reasons of leaving education at early age. In the province of Sindh, total enrollment in primary, middle, secondary and higher secondary schools was dropped from 440,2993 to 404,4476 between years 2010-2015 (Statistics S. B., 2017). Similarly, in the province of Punjab, enrollment in primary schools between years 2004-2014 fell from 4875 to 4178 students (Bureau of Statistics, 2016). Correspondingly, decline rate is also observed in Khyber Pakhtunkhwa where enrollment in Primary schools 
was dropped from 301,2593 to 300,3841 between years 2013 to 2015 (Statistics B. o., 2017). Overall dropout rate in Pakistan is evident when $72 \%$ enrolment from primary schools declines to $31 \%$ at high school stage. (Chaudhary, 2016).

\section{Enrolment drops drastically at the middle and high school stage}

\section{Net enrolment at primary stage is $72 \%$; this drops to $47 \%$ at the middle and $31 \%$ at the high school stage.}

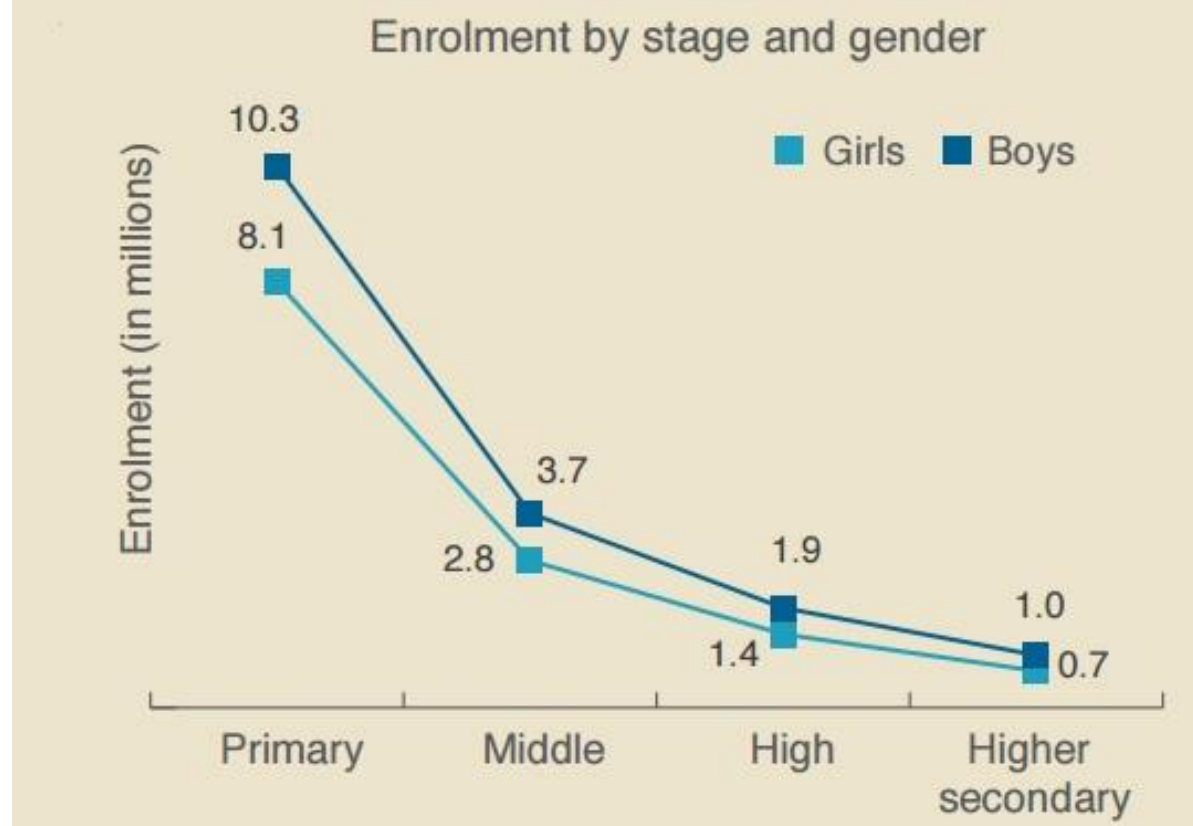

Figure No. 2. "Why do so many children drop out of Pakistani schools?", . Chaudhary, H. (2016, Feburary 25), Retrieved from Dawn News: https://www.dawn.com/news/1241630

\subsection{Children Disrespectful Behaviors and Unlawful Acts}

Children from disintegrated family often show impolite behavior with elders and peers, and such conduct is more obvious when domestic violence, use of abusive language, disrespectful attitude, frequent arguments and conflicts between parents are common. If the children are in adolescence age, they show detached and independent behavior from parents, where friends replaces parents' position, and where social life is stronger than household life (Pickhardth, 2011). This leads towards the development of disrespectful behavior for parents, when child starts feeling that parents are no more required. Such children are excessively engaged in adverse companies, developing indecorous responses, ultimately leading towards the growth of behavior issues (Magpantay, 2014). The more independent-minded adolescent shows violence to separation, often reacts in a furious, incontrollable way, displays disrespect to family norms and executes rebellious acts as parents have failed to keep family integrated (Pickhardth, 2011) and often reported showing immoral behaviour (Ayobami, 2021). Children raised apart from their fathers have higher risks of misbehavior, involvement in criminal activities, and imprisonment. More than twenty years ago, Dr. Urie Bronfenbrenner, stated that children with single parents were ill mannered and showed more involvement in illegal acts even after being provided financial assistance (Wardle, 2011). The National Report on Juvenile Offenders and Victims from the U.S. Department of Justice has also revealed that juveniles who lived in segregated families had higher law violating behaviors than the children living with both parents. Princeton University research has shown that tendency among boys from broken families is two to three times more to commit a 
delinquency leading to imprisonment by the time they are in their early thirties, and this behavior is common despite they have different race, family circumstantial, locality, and intellectual ability. The percentage is more noticeable when children raised away from father and are in supervision of mother only (ibid). Criminal acts including sexual harassment is also more common among the children of disintegrated families. Polaschek in 1997 stated that, the strongest factor that stimulate men for sexual harassment is to overcome aggression developed from discord families, where they were neglected and spent time in penal institutions (Poktnik \& Kouyoumdjian, 2011). Indian newspaper stated that children from disturbed and broken families have more indulgence in sexual activities, as there is no one to keep a watch on their activities and most of the time purpose of such involvements is to have fun and pleasure of harassing others (Grewal, 2013). In Pakistan, oppressive culture is getting practiced and most of the time purpose of bullying in educational institutions, is to shed frustration developed due to violence and disturbance at home. The mode to shed frustration developed into sexual harassment activities in early adolescences, which make them habitual of such acts and criminal convictions.

Children from conflicted families are found more in delinquent and criminal acts in Pakistan. In Faisalabad jail, where 70 percent teen-agers involved in murder attempts, had tough house hold life and their parents had consistent arguments on social and economic issues (Talpur, Pathan, \& Shah, 2012).

\subsection{Children Trust Issues and Insecurities}

Healthy relationships foster on trust, but when relationship ends due to the breakdown of trust between parents, children start developing trust issues and these persist in their future relations. If any of the parent cheated onto other, children develop rage, anger and offensive behavior which will continue to foster even when child is grown into an adult (Philpott, 2013). Children of such families often develop insecurities and instabilities (Pickhardth, 2011; Falculan et al., 2019). According to research of Dinah and Tumuti in 2012, divorce or separation of parents results in destruction of child's psychology and also raises the probability that they will never marry, due to fear of divorce or disloyalty from companion. Moreover, children in divorced families tend to have unconfident emotive strength with parents and often see family as a frightening subject (Firdausi, Hotifah \& Simon, 2020). Thus, such sufferings had lowered the average level of child's comfort, where child when turned into an adult, suffered from fear of disloyalty and getting into permanent relationships (McGuirk \& Mai, 2016). Research Study has indicated that separated parents' children have higher tendency of divorces where 60 out of 100 daughters and 35 out of 100 sons are unable to remain in their wedding status because they have received a non-direct message from their parents, that end of companionship is acceptable (Philpott, 2013). 


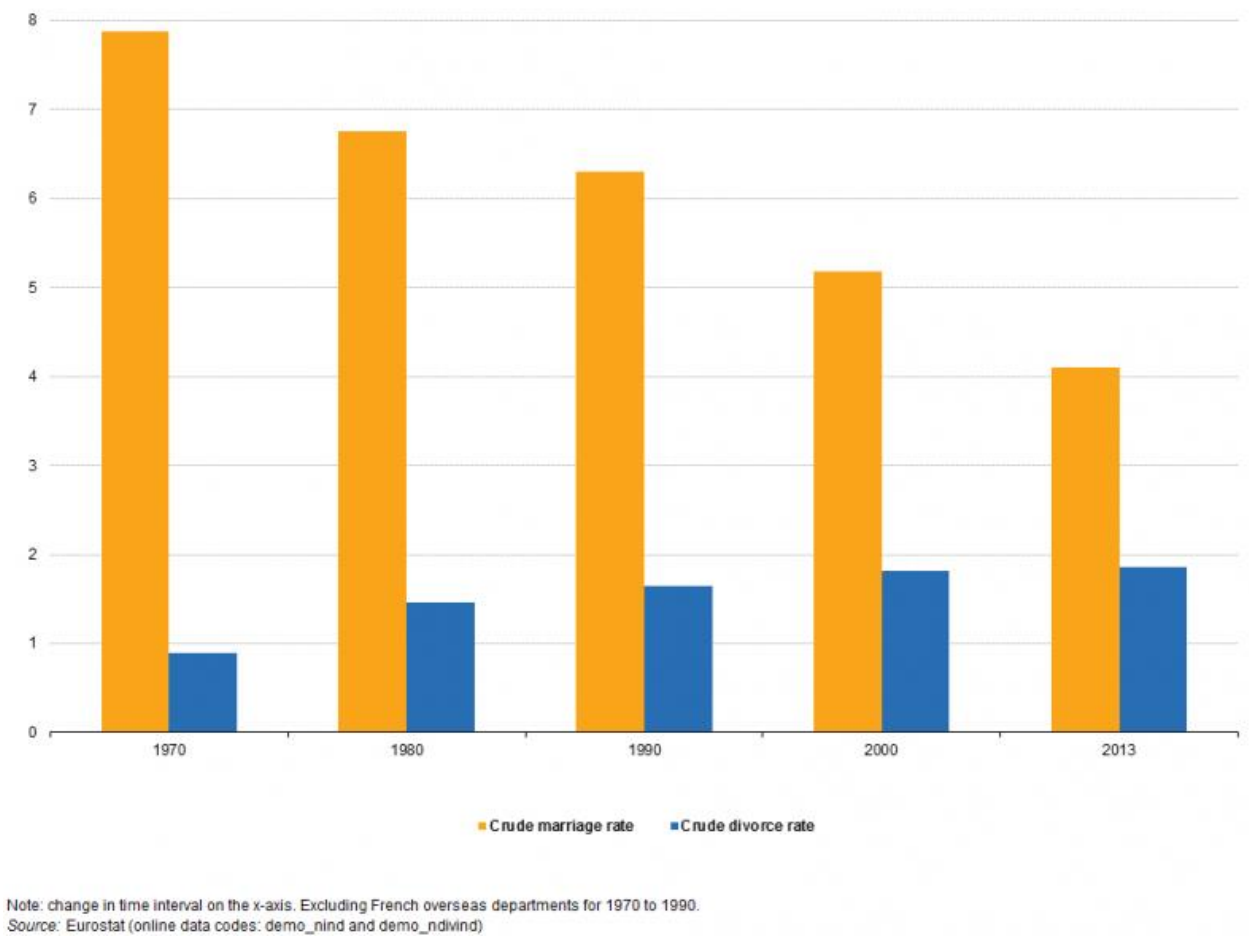

Figure No. 3. Marraige and Divorce Statistics, Anonymous, June 2017, Retrieved from euro state statistics explained: http://ec.europa.eu/eurostat/statisticsexplained/index.php/Marriage_and_divorce_statistics

Increasing divorce rate in last few decades is evident from statistical data of Europe. This is creating a rhythmic repetition of disintegrated families, as child from divorced parent when grow up into an adult, is unable to indulge in a successful family life, which leads towards the end of companionship. Divorce rate is almost doubled from 1970 to 2013 as children from broken families when grew up into an adult, remained unsatisfied from spouses and companionship, resulted in disintegration.

\subsection{Technological Threats in Disintegrated Families}

Increased use of technology among children has also increased distances among family members in several ways. Children's engagement in technology, has made them so busy that they hardly communicate with their parents when they arrive home and about half of the time totally ignore their parents' presence. Amusingly, children feel ignorant and insecure about parents when spent most of the schedule in social networking. Absence of the parents has increased children's indulgence in technology without any surveillance. Continuous use of technology has increased children expertise in the use of the gadgets. Feeling of being superior in the use of electronic devices, makes children disrespectful and argumentative, especially when parents' try to control unnecessary use. Social networking has increased children's communication with friends without any observation and parental monitoring (Taylor, 2013). Extensive time spent on internet not only intensify detachment from parents, but children has gained opportunities to reach unethical, immoral information, including adult's content and shameful material (Shin \& Ismail, 2014). In case of parental separation, kids have additional freedom to indulge in social networking sites, leading towards the attainment of undesirable characters in their personalities, which later surges into acts of delinquency and crime. In Pakistan, use of internet and mobile communication is economical which has made children easy access to social networking. In absence of parents' supervision, children learn many unethical contents which leads towards the destruction of their personalities.

\section{Discussion and Conclusion}

The review of the articles has suggested that family ties are an important institution that help children to develop into responsible and healthy human beings. But, increasing disintegration rate has negatively influenced the growth of the children and resulted in the development of insecurities, trust issues, delinquent nature, immoral behavior, psychological issues, and unsuccessful completion of education. In case of 
parental separation, kids have additional freedom to indulge in social networking sites, leading towards the attainment of undesirable characters in their personalities. These hostile effects on children's development are not only to temporary basis but it continues and persists even when child transit into an adulthood. It is necessary to bring reforms to the cultural and social structure to reduce the divorce rate and to create a healthy, fostering, and progressive civilization. Based on the conclusions, following recommendations are suggested.

\section{Recommendations}

The goal of this paper is to highlight outcomes and sufferings of children in different aspects of life such as psychology, physical fitness, educational accomplishment and marital decision, after family disruption or disintegration. Researches clearly demonstrated that children coming from broken families have more traumatic circumstances, while juveniles from the intact families have higher aptitudes and stronger feelings (McGuirk \& Mai, 2016). However, stigma of family separation can be controlled with some strategies.

- As recommended by Waseem at el., (2020) to control divorces in Pakistan it is necessary to make some changes in cultural and societal believes. Early and forced marriages need to be controlled by education which will help sufferers to present and justify their reservations and convictions with stronger justifications. It is recommended that marriages should be taken place between families with equal status, as inequalities generates glitches and conflicts in adjustments among spouses leading towards the end of relationship (Hassan, 2015).

- In Pakistan, divorced women are more susceptible to physical and psychological problems such as extensive fearful concerns, melancholy, feeling of isolation, insomnia, loss of appetite, distraction and loss of concentration on work (Nizamuddin, 2017; Waseem et al., 2020). Females who are themselves mentally unfit, if left over with children to raise, will not be able to accomplish children needs, mainly due to health and financial issues. At the time of the divorce, the competent authority should consider these factors and support women socially and economically. Stipend for the children should be given to women for proper upbringing of the children. Along with healthcare facility for mother and children, counseling sessions should be conducted to overcome trauma of getting divorced. Cognitive behavioral therapy is considered as a useful tool for dealing with such cases. Some psychologist should be hired to help clients express their fears, anxieties and constructively explore their past- coping strategies.

- Individual parent may be an excellent caregiver, but its households are insufficient to provide richer environment for child's development (Garbarino, 2009). In case, parent is single, it's a high time for a parent to help child develop all aspects of its personality. For this parent has to make arrangements, where child can meet other elderly persons in the family such as grandparents, uncles, aunts where social learning can help child to overcome weaknesses developed in child's character due to nonattendance of separated parent. Child's societal sphere, including relatives, neighbors and mates, plays pivotal role in enhancing child's abilities such as making judgments, selection of apposite choices, introducing responsible behavior with useful contribution in social events, and gaining respect, which in turn protects child from negative effects of scarcity, unhappiness and suspicion (Asadullah \& Shah, 2016).

- Now a days children are more independent when they are more involved in social networking (Shin \& Ismail, 2014; Taylor, 2013). It's a crucial time for a single parent to be more vigilant to avoid technological drive, creating division between themselves and their children. Over involvement in networking creates a disrespectful environment when children become argumentative with disputed behavior, as they have impression that parents are no more interested in their activities and are engaged with their priorities.

- On a community level, counsellors can provide guidance and emotional support to the children after their parents' divorce. Counsellor can help members of separated family in identifying community resources and provide social services to help dealing with stigma (Abu Ghali, 2017). Similarly, awareness sessions can help to improve mental and physical health, aid in identifying tactics to overcome trauma (Nizamuddin, 2017).

- Pakistan's family law allows Khula without the consensus of the husband (oxymoronically defeating the entire purpose of the Islamic right to Khula) (Ramzan et al., 2018). This regulation is against Islamic Ideology but still it is followed making the concept of strong committed families weaker. It needs to be reversed (Tariq, 2009). 
- Upbringing of the children should be made in the way that they have clear concept of responsibilities and bearing of the married life. Wedding is the agreement to give respect to spouse decisions (Tariq, 2009). Educational institution should raise the awareness about the commitments in marriages especially in adolescent and in adult age.

- Policy Makers need to make policies to control increasing divorce rate in Pakistan. It is evident from history that old-style family i.e., presence of both parents is the finest setting for children's nurture as a responsible citizen (Tariq, 2009). So, it is important for the policy makers to take strong actions against divorced applicant especially if they have children to raise. Cultural and authorized strategies should be incorporated such as introduction of economic, social and psychological resources to make matrimony relations long lasting, reducing the risks in children's lives, including parental separation/divorce (D’Onofrio, 2011).

- In order to avoid development of disrespectful behavior among children, parents need to show humbleness towards each other, consider ex-spouse with dignity to teach children that disagreement doesn't mean to disrespect any parent (Philpott, 2013).

- In order to fulfill space in child's personality due to absence of a parent, routines visit should be made, so the child knows parents are as lovingly connected to the child as ever and assure them that parents are always there to fulfill child's needs (Philpott, 2013).

- End of relationship with divorce is something which is disliked by ALLAH, but it is allowed because there are situations where divorce is the only option and divorce is the only answer. (Tariq, 2009). In the Quranic Verses of Surah-Al-Baqarah it is stated:

"And if you fear that the two (i.e.) Husband and wife) may not be able to keep the limits ordered by ALLAH, there is no blame on either of them if she redeems herself from marriage tie". When there is no other solution, it is suggested to disclose relationship sufferings to children, before giving them a shock or trauma of being divorced. Conversations to children about a divorce is challenging, however following tips can help both the child and parents to encounter stress of these discussions. Parents can make children prepare by gradual sharing their sufferings and termination of companionship before declaring it to the child at the last moment. It is advisable to share about end of relationship when both spouses are together. It is suggested that parents make a straightforward announcement and do not create statement complex by revealing unrequired information. It is necessary to assure child that end of relationship is sad but both parents love them always and will be there for them anytime. To keep relationship respectful and strong it is necessary not to disclose spouse faults with the children (Divorce and Children, 2013).

\section{REFERENCES}

Abu Ghali, E. M. (2017). The Effectiveness of a Counseling Program in Developing Psychological Resilience to Handle Stress among Female Adolescents from Broken Families. Journal of Educational \& Psychological Sciences, 18(01), 407-444.

Anonymous. (2016, June 27). Rising Divorce Rates. Retrieved from The Nation: http://nation.com.pk/editorials/27Jun-2016/rising-divorce-rates

Anonymous. (2017, June). Marraige and Divorce Statistics. Retrieved from euro state statistics explained: http://ec.europa.eu/eurostat/statistics-explained/index.php/Marriage_and_divorce_statistics

Asadullah, \& Shah, M. (2016, December 15). Incapacitated decision making power, over emphasized obedience and its exclusionary effects on children. Retrieved from Journal of Social Inclusion: https://josi.journals.griffith.edu.au/index.php/inclusion/article/view/497

Ayobami, A. M. (2021). INFLUENCE OF BROKEN HOME ON MORAL BEHAVIOUR OF IN-SCHOOL ADOLESCENTS IN OYO TOWN, NIGERIA. Trailblazer International Journal of Educational Research, 1(1).

Bureau of Statistics, G. o. (2016). 2016 Statistical Pocket Book of the Punjab. Lahore: Bureau of Statistics, Government of Punjab.

Chaudhary, H. (2016, Feburary 25). Why do so many children drop out of Pakistani schools? Retrieved from Dawn News: https://www.dawn.com/news/1241630

Churchill, P. F. (2012, Jan 11). The Effects of Divorce on Children. MARRI (Marriage and Religion Research Institute) Research, 1-48. Retrieved from MARRI Marraige and Religion Research Institute.

D’Onofrio, B. M. (June 2011). Consequences of Separation/Divorce for Children. Encycloperdia on Early Child Development, 1-5. 
Demir-Dagdas, T., Isik-Ercan, Z., Intepe-Tingir, S., \& Cava-Tadik, Y. (2018). Parental divorce and children from diverse backgrounds: Multidisciplinary perspectives on mental health, parent-child relationships, and educational experiences. Journal of Divorce \& Remarriage, 59(6), 469-485.

Divorce and Children. (2013, December). Retrieved from American Academy of Child and Adolescent Psychiatry : http://www.aacap.org/AACAP/Families_and_Youth/Facts_for_Families/FFF-Guide/Children-and-Divorce001.aspx

Falculan, R. M., Paula, P. A., Ocdamia, J. J. J., \& Samiley, S. G. G. (2019, December). Lived Experiences of Young Adults From Broken Families on Marital Relationships. In Abstract Proceedings International Scholars Conference (Vol. 7, No. 1, pp. 512-529).

Firdausi, N. I. A., Hotifah, Y., \& Simon, I. M. (2020). Psychological Dynamics of Young People on Broken Home Families. Acta Counseling and Humanities, 1(1), 31-41.

Garbarino, J. (2009). Children and Families in the Social Environment : Modern Applications of Social Work. Somerset, United States: Taylor \& Francis Inc.

Green, B. N., Johnson, C. D., \& Adams, A. (2006). Writing narrative literature reviews for peer-reviewed journals: secrets of the trade. Journal of chiropractic medicine, 5(3), 101-117.

Grewal, M. D. (2013). Educationists say falling moral values, media responsible for increasing sexual harrasement. PAtiala: Hindustan Times.

Goisis, A., Özcan, B., \& Van Kerm, P. (2019). Do children carry the weight of divorce?. Demography, 56(3), 785-811.

Haider, M. (2014, Feburary 19). The continued abuse of the Pashtun woman. Retrieved from Dawn News: https://www.dawn.com/news/1088086

Harold, G. T., \& Sellers, R. (2018). Annual research review: Interparental conflict and youth psychopathology: An evidence review and practice focused update. Journal of Child Psychology and Psychiatry, 59(4), 374-402.

Hassan. (2015, June 10). PAKISTAN DIVORCE RATE INCREASING. Why? Retrieved from Baaghi: https://www.baaghi.tv/pakistan-divorce-rate-increasing-why/

Hetherington, E. M. (1972). Effects of father absence on personality development in adolescent daughters. Developmental Psychology, 7(3), 313-326. HYPERLINK "https://psycnet.apa.org/doi/10.1037/h0033339" It "_blank" https://doi.org/10.1037/h0033339

Jivani, K. K., \& Minaz, A. (2019). Sex Health Education: A Cultural Taboo in Pakistan. i-Manager's Journal on Nursing, 9(3), 38

Mackay, R. (2005). The Impact of Family Structure and Family change on Child Outcomes: A Personal Reading of the Research Literature. Social Policy Journal(24), 111-133. Retrieved from Ministry of Social Development.

Magpantay, M. J., Malabrigo, P., Malijan, R. J., \& Manarin, M. G. (2014). Behavioral problems and coping strategies of selected adolescents belonging to a broken family. CAM Research Journal, 2(1), 112-135.

McGuirk, K. R., \& Mai, T. X. (2016, August 11). THE IMPACT OF BROKEN FAMILY ON CHILD OUTCOMES: PSYCHOLOGY AND DECISION FOR THE FUTURE MARRAIGE. ICESI 2016 The International Conference on Education and Social Integration (pp. 1-9). Ho Chi Minh: Ton Duc Thang University.

Muhid, A., \& Kurniadi, D. (2021). An Analysis on the Impact of a Broken Family Towards the Children's Behaviour as Seen in Novel Rainbirds. Jurnal CULTURE (Culture, Language, and Literature Review), 8(1), 77-88.

Nizamuddin, M. (2017, January 26). Rising Divorce Rates in Pakistan - Its Impact on the Individual and Society. Retrieved from JPMS-Journal of Pioneering Medical Sciences Blog: http://blogs.jpmsonline.com/2017/01/26/rising-divorce-rates-in-pakistan-its-impact-on-the-individual-andsociety/

Ngure, W. W., Paul, P., \& Amollo, O. (2017). Influence of parental marital status on academic achievement of preschool children in Embakasi, Nairobi, Kenya. International Journal of Social Science and Humanities Research, 5(2), 37-42.

Paula Fomby, A. J. (2007). Family Instability and Child Well-Being. US National Library of Medicine National Institue of Health, 181-204.

Philpott, S. (2013, March 25). The Effect of Divorced Parents on a Child's Future Relationships. Retrieved from The kids: https://mom.me/kids/6576-effect-divorced-parents-childs-future-relationships/

Pickhardth, C. E. (2011, December 19 ). The Impact of Divorce on Young Children and Adolescents. Retrieved from Psychology Today: https://www.psychologytoday.com/blog/surviving-your-childs-adolescence/201112/theimpact-divorce-young-children-and-adolescents

Poktnik, R., \& Kouyoumdjian, H. (2011). Sexual Harrsasement and Aggresion. In R. Poktnit, \& H. Kouyoumdjian, Introduction to Psychology (9 ed., p. 603). Belmont, CA, USA: Wadsworth.

Ramzan, S., Akhtar, S., Ahmad, S., Zafar, M. U., \& Yousaf, H. (2018). Divorce status and its major reasons in Pakistan. Sociology \& Anthropology, 6(4), 386-391. 
Shin, W., \& Ismail, N. (2014). Exploring the role of parents and peers in young adolescents' risk taking on social networking sites. Cyberpsychology, Behavior, and Social Networking, 17(9), 578-583.

Statistics, B. o. (2017). Development Statistics of Khyber Pakhtunkhwa 2017. Peshawar: Bureau of Statistics, Planning and Development Department, Khyber Pakhtunkhwa.

Statistics, S. B. (2017). School Education Statistics Sindh 2014-2015. Karachi: Planning and Development Department, Government of Sindh.

Streeck-Fischer, A., \& van der Kolk, B. A. (2000). Down will come baby, cradle and all: diagnostic and therapeutic implications of chronic trauma on child development. Australian and New Zealand Journal of Psychiatry(34), 903-918.

Talpur, F., Pathan, P. A., \& Shah, P. (2012). EXAMINING THE CAUSES OF JUVENILE DELINQUENCY IN PAKISTAN. The Women-Annual Research Journal of Gender Studies, 4, 33-43.

Tariq, K. (2009, November 17). High Rate Of Divorce In Pakistan. Retrieved from Hamariweb: http://www.hamariweb.com/articles/article.aspx?id=5043

Taylor, J. (2013, March 13). Is Technology Creating a Family Divide? Retrieved from Psychology Today : https://www.psychologytoday.com/blog/the-power-prime/201303/is-technology-creating-family-divide

Towe, V. L., ul Hasan, S., Zafar, S. T., \& Sherman, S. G. (2009). Street life and drug risk behaviors associated with exchanging sex among male street children in Lahore, Pakistan. Journal of Adolescent Health, 44(3), 222-228.

Wardle, L. D. (2011). The Disintegration of Families and Children's Right to Their Parents. Ave Marie Law Review, $10(1), 1-52$.

Waseem, J., Muneer, R., Hoor-Ul-Ain, S., Tariq, R., \& Minhas, A. (2020). Psychosocial determinants of divorce and their effects on women in Pakistan: a national review. International Journal of Human Rights in Healthcare. 